\title{
Phenotypic and genotypic characterization of methicillin and vancomycin resistant staphylococci
}

\author{
Sahar T. M. Tolba*, Einas H. El-Shatoury, Nagwa A. Abdallah and Samah A. Mahmoud \\ Microbiology Department, Faculty of Science, Ain Shams University, Cairo, Egypt.
}

Accepted 6 November, 2013

\begin{abstract}
One hundred (100) staphylococci were isolated from several Egyptian hospitals and laboratories which include 85 clinical isolates and 15 from hospital surroundings. The isolates were identified by conventional and molecular techniques. Fifty $(50)$ isolates were identified as Staphylococcus aureus (SA), 40 were Staphylococcus epidermidis (SE) while 10 were identified as Staphylococcus species (SS). Upon testing the resistance to methicillin and vancomycin, it was found that resistance is dominant in isolates from clinical samples than those from the surrounding surfaces. Moreover, the resistance to methicillin was higher than that to vancomycin. Multiplex polymerase chain reaction was carried out to characterize the staphylococci-specific region of 16S rRNA gene, mecA gene associated with methicillin resistance and the virulence marker-associated genes Panton-Valentine leukocidin (PVL) IukS/F-PV genes which are responsible for leukocyte destruction and tissue necrosis. All the methicillin resistant staphylococci (MRS) were found to be mecA $^{+}$while only five MRS carried IukS/F-PV genes. On the other hand, $30 \%$ of the methicillin sensitive staphylococci (MSS) were found to harbor the mecA gene while lacking the PVL. The results highlight the important role of horizontal gene transfer of virulence genes between staphylococci. In addition, this study indicates that the use of multiplex PCR is not sufficient for antibiotic susceptibility prediction and thus the simultaneous use of conventional and multiplex PCR technique is required for the identification of staphylococci and determination of their antibiotic susceptibility.
\end{abstract}

Key words: Methicillin resistance, Staphylococcus aureus, Staphylococcus epidermidis, mecA, PantonValentine leukocidin (PVL).

\section{INTRODUCTION}

Staphylococci are opportunistic human pathogen capable of causing a wide variety of diseases. The severity of a staphylococcal infection and its response to antibiotic treatment is dictated by the specific suite of virulence and antibiotic resistance associated genes (Peacock et al., 2002). Staphylococci impose challenge to clinicians, not only because of vancomycin and methicillin resistance, but also because of resistance to many other antibiotics (Levy and Marshall, 2004). Detection of methicillin resistance can be difficult due to the presence of two subpopulations, one susceptible and the other resistant that may coexist within a culture of staphylococci. This phenomenon is termed heteroresistance. Results using conventional phenotypic assay may be given after $48 \mathrm{~h}$ or more. In case of severe disease, the early detection of MRSA is essential. Thus detection of mecA gene using PCR is considered to be the best method (Prere et al., 2006).

Hospital associated methicillin resistant Staphylococcus aureus (HA-MRSA) acquired an integrated sequence into their genome (21-67-kb mobile genetic element), termed staphylococcal cassette chromo-some mec (SCCmec), which harbours the methicillin resistance gene mecA (Ito et al., 2001, 2004). The SCCmec chromosome contains 
mecA gene and two regulatory genes mecl and mecR 1 which constitute mec complex that play an important role in the regulation of the mecA gene (Archer and Bosilevac, 2001; Berger-Bachi and Rohrer, 2002). Community-associated MRSA strains carry the PantonValentine leukocidin (PVL) virulence genes possessing a small mobile staphylo-coccal cassette chromosome mec (SCCmec) type IV or V genetic element which harbors the methicillin resistance $(\operatorname{mec} A)$ gene and which is more easily transferred to other strains of $S$. aureus than the larger SCCmec types (types I to III) that are prevalent in hospital associated MRSA strains (Vandenesch et al., 2003; Zhang et al., 2004).

McClure et al. (2006) developed a multiplex PCR to detect the staphylococci specific region of 16SrRNA gene along with virulence genes such as Panton-Valentine leukocidin (PVL) lukS/F-PV genes; which is responsible for leukocyte destruction and tissue necrosis and mecA gene associated with methicillin resistance. Concordance between phenotypic and genotypic characteristics was recorded.

The aim of this work was to determine whether the use of multiplex PCR amplifying these three genes would suffice the identification and prediction of virulence and the antibiotic susceptibility pattern of isolated staphylococci.

\section{MATERIALS AND METHODS}

\section{Bacterial isolates}

A total of 100 clinical and hospital surroundings samples were collected from five different hospitals in Cairo. Samples from blood, urine, sputum, pus, throat, wound swabs, soil and patient beds were collected.

Samples were first collected on nutrient agar plates, purified and then sub-cultured on plates of blood agar, mannitol salt and BairdParker agar medium (Oxoid) using the streak plate method. The plates were incubated at $37^{\circ} \mathrm{C}$ for 24 - $48 \mathrm{~h}$. Preliminary identification was carried out as recommended by Mahon and Manusekis (1995), Chapin and Lauderdale (2003) and Todar (2005). Gram stain, catalase and coagulase production were carried out to identify staphylococcal isolates (Cheesbrough, 1984; Koneman, 1992).

\section{Antibiotic susceptibility test}

Muller Hinton plates were inoculated with 0.5 McFarland standard inocula then different antibiotic disks were placed on the surface of the agar plates (methicillin $6 \mu \mathrm{g}$, ampicillin $10 \mu \mathrm{g}$, vancomycin 10 $\mu \mathrm{g}$, linezolid $30 \mu \mathrm{g}$, clindamycin $2 \mu \mathrm{g}$, ciprofloxacin $10 \mu \mathrm{g}$, tobramycin $10 \mu \mathrm{g}$, erythromycin $15 \mu \mathrm{g}$, doxacycline $30 \mu \mathrm{g}$ and cefoperaone $75 \mu \mathrm{g}$ ). The antibiotic susceptibility test was carried out according to Kirby-Bauer disk diffusion susceptibility test protocol (Bauer et al., 1966) and the inhibition zones were measured as recommended by NCCLS (1997).

\section{Determination of minimal inhibitory concentration (MIC)}

Minimal inhibitory concentration of methicillin and vancomycin was tested according to Washington and Wood (1995) and NCCLS (1997).

Staphylococci are considered methicilin resistant (MRSA) if their MIC for oxacillin is $\geq 4 \mu \mathrm{g} / \mathrm{ml}$ and they are considered vancomycin resistant (VRSA) if their MIC for vancomycin $\geq 16 \mu \mathrm{g} / \mathrm{ml}$ (NCCLS, 1997).

\section{Polymerase chain reaction}

Genomic DNA was extracted from the bacterial isolates according to Sambrook et al. (2001). PCR were performed with three primer pairs. The first pair is mecA1 (5'GTAGAAATGACTGAACGTCCGATAA-3') and mecA2 (5'CCAATTCCACATTGTTTCGGTCTAA-3') corresponding to the mecA gene which encodes the unique penicillin-binding protein associated with oxacillin resistance in staphylococci (Zhang et al., 2004). The second pair is Staph756F (5'AACTCTGTTATTAGGGAAGAACA-3') and Staph750R (5'CCACCTTCCTCCGGTTTGTCACC-3') corresponding to regions of 16S rRNA genes that are unique to staphylococci (Zhang et al., 2004). The third pair is LukPV-1 (5'ATCATTAGGTAAAATGTCTGGACATGATCCA-3') and LukPV-2 (5'-CATCAAGTGTATTGGATAGCAAAAGC-3') corresponding to the virulence marker (PVL) lukS-PV and lukF-PV genes that encode for tissue necrosis in staphylococcal infection (Lina et al., 1999). The PCR amplification products of the three primer pairs mecA, 16S rRNA and PVL genes are 310, 756 and $433 \mathrm{bp}$, respectively.

A routine laboratory PCR method for the detection of lukS-PV genes and mecA gene have required the use of separate PCR programs to investigate the proper conditions for each gene (Van $\mathrm{Hal}$ et al., 2007). Multiplex PCR conditions were performed according to McClure et al. (2006) and Van Pelt-Verkuil et al. (2008). One micro liter of DNA was added to $30 \mu \mathrm{l}$ final reaction volume containing $3 \mu \mathrm{l}$ primers mix (10 pmol specific for 16 srRNA, lukS-PV and mecA genes), $3 \mu \mathrm{l}$ Taq Buffer (10x), $1.8 \mu \mathrm{l} \mathrm{Taq}$ Enzyme (25 Mmol mgcl), $3 \mu \mathrm{l}$ (2Mmol DNTPase) and $13.7 \mu \mathrm{l}$ nuclease-free distilled $\mathrm{H}_{2} \mathrm{O}$. The $\mathrm{PCR}$ was performed using $A B$ Applied Biosystems thermocycler 2720. The PCR protocol was one denaturation step at $95^{\circ} \mathrm{C}$ for $5 \mathrm{~min}$, followed by 25 cycle of denaturation at $95^{\circ} \mathrm{C}$ for $1 \mathrm{~min}$ annealing at $57^{\circ} \mathrm{C}$ for $1 \mathrm{~min}$ and primer extension at $72^{\circ} \mathrm{C}$ for $1 \mathrm{~min}$, post extension step at $72^{\circ} \mathrm{C}$ for $10 \mathrm{~min}$. Amplified PCR products were recognized in $0.8 \%$ agarose gel stained with ethidium bromide.

\section{RESULTS}

Eighty five (85) staphylococcal isolates were from clinical samples and 15 from hospital surfaces. Data were collected based on colony morphology, growth on blood agar media, mannitol salt agar media and Baird-Parker agar media, catalase and coagulase tests. Fifty isolates produced golden yellow colonies on mannitol salt agar medium and they were positive for catalase and coagulase. Thus, they were identified as $S$. aureus (SA). Forty isolates formed pink colonies on mannitol salt agar medium and were tested positive for catalase production but negative for coagulase and were identified as Staphylococcus epidermidis (SE). Ten isolates were atypical to either SA or SE. Therefore they were designnated as Staphylococcus species (SS). The percentage of occurrence is shown in Table 1. The highest occurrence of staphylococci was found in wound infections 
Table 1. Sources and numbers of staphylococcal isolates, S. aureus (SA), S. epidermidis (SE) and unidentified Staphylococcus sp. (SS).

\begin{tabular}{lcccc}
\hline Source & Total number (\%) & No. of SS isolates & No. of SE isolates & No. of SA isolates \\
\hline Floor & 6 & 1 & 2 & 3 \\
Lab bench & 3 & 0 & 1 & 2 \\
Patient bed & 6 & 1 & 3 & 2 \\
Blood & 9 & 0 & 4 & 5 \\
Urine & 19 & 2 & 10 & 7 \\
Sputum & 7 & 0 & 2 & 5 \\
Pus discharge & 12 & 2 & 3 & 7 \\
Wound swab & 21 & 1 & 7 & 13 \\
Throat swab & 11 & 1 & 6 & 4 \\
Ear swab & 3 & 0 & 1 & 2 \\
Cerebrospinal fluid (CSF) & 1 & 1 & 0 & 0 \\
Pleural fluid & 1 & 1 & 0 & 0 \\
Cerebral fluid & 1 & 0 & 1 & 0 \\
Total no & 100 & 10 & 40 & 50 \\
\hline
\end{tabular}

Table 2. Distribution of methicillin resistant staphylococci (MRS) and vancomycin resistant staphylococci (VRS) according to their minimal inhibitory concentration (MIC).

\begin{tabular}{lcccccc}
\hline & \multicolumn{2}{c}{$(\mathbf{S A})(\mathbf{n}=\mathbf{5 0})$} & \multicolumn{2}{c}{$(\mathbf{S E})$} & $(\mathbf{n}=\mathbf{4 0})$ & \multicolumn{2}{c}{$(\mathbf{S S})(\mathbf{n}=\mathbf{1 0})$} \\
\cline { 2 - 7 } Resistance (\%) & $\begin{array}{c}\text { Sur } \\
(\mathbf{n}=\mathbf{7})\end{array}$ & $\begin{array}{c}\text { Clin } \\
(\mathbf{n}=\mathbf{4 3})\end{array}$ & $\begin{array}{c}\text { Sur } \\
(\mathbf{n}=6)\end{array}$ & $\begin{array}{c}\text { Clin } \\
(\mathbf{n}=\mathbf{3 4})\end{array}$ & $\begin{array}{c}\text { Sur } \\
(\mathbf{n}=\mathbf{2})\end{array}$ & $\begin{array}{c}\text { Clin } \\
(\mathbf{n}=\mathbf{8})\end{array}$ \\
\hline MRS (MIC $\geq 4 \mu \mathrm{g} / \mathrm{ml})$ & $28.5 \%$ & $53.5 \%$ & $0 \%$ & $41 \%$ & $100 \%$ & $100 \%$ \\
VRS (MIC $\geq 16 \mu \mathrm{g} / \mathrm{ml})$ & $0 \%$ & $25.5 \%$ & $0 \%$ & $32.5 \%$ & $0 \%$ & $25 \%$ \\
\hline
\end{tabular}

followed by urine samples. In addition, SA strains were more dominant in wound infections while (SE) strains were more dominant in urine samples.

Antibiotic susceptibility test showed multi-drug resistance to tested antibiotics with various extents. Forty seven percent of all tested staphylococci were resistant to methicillin, $31 \%$ were resistant to vancomycin, $52 \%$ to ampicillin, $40 \%$ to ciprofloxacin, tobramycin and erythromycin, $36 \%$ to doxacyclin, $33 \%$ to clindamycin and $7 \%$ were resistant to linezolid.

MIC of methicillin and vancomycin were measured for all the staphylococcal strains. Strains able to grow at concentration 1 to $<4 \mu \mathrm{g} / \mathrm{ml}$ were considered sensitive to methicillin (MSS) while methicillin resistant staphylococci (MRS) were those able to grow at concentration $\geq 4$ $\mu \mathrm{g} / \mathrm{ml}$. Concerning MIC to vancomycin, vancomycin resistant staphylococci (VRS) were those that were able to grow at concentration $\geq 16 \mu \mathrm{g} / \mathrm{ml}$. Isolates from the hospital surfaces were all sensitive to vancomycin. Staphylococci resistant to methicillin and vancomycin were more dominant in clinical isolates than the isolates from the hospital surface (Table 2). Moreover, the percentage of MRS was higher than that of VRS in clinical isolates. All tested resistant staphylococci showed high MIC values to both methicillin and vancomycin (Figure 1). Ten percent of both SA and SE were resistant to methicillin at concentration of $32 \mu \mathrm{g} / \mathrm{ml}$. Moreover, 3 out of $50(6 \%)$ of SA and 3 out of $40(7.5 \%)$ of SE were resistant to vancomycin at concentration of $64 \mu \mathrm{g} / \mathrm{ml}$. Fifty percent of SA and $35 \%$ SE strains were resistant to methicillin at concentration of $\geq 4 \mu \mathrm{g} / \mathrm{ml}$. while 22 and $27.5 \%$ of the SA and SE strains were resistant to $\geq 16$ $\mu \mathrm{g} / \mathrm{ml}$ of vancomycin. Resistance of SS strains were relatively high as $70 \%$ of the strains were resistant to 16 $\mu \mathrm{g} / \mathrm{ml}$ methicillin and $100 \%$ of the strains were resistant to $\geq 4 \mu \mathrm{g} / \mathrm{ml}$, while $10 \%$ were resistant to $32 \mu \mathrm{g} / \mathrm{ml}$ vancomycin (Figure 1).

Single-targeted PCR products that were amplified from 16S RNA, mecA and PVL genes were 100\% congruent with those targeting the three genes collectively in multiplex PCR. Multiplex PCR was carried out for all staphylococci isolates. All isolates were positive for the 16S rRNA gene specific for staphylococci. All MRSA and MRSE were found to have mecA gene. However, thirty percent of the phenotypically MSSA and MSSE were found to harbor mecA gene. Furthermore PVL gene was detected in five percent of the isolates. PVL positive isolates were SA strains recovered from wound infection, 

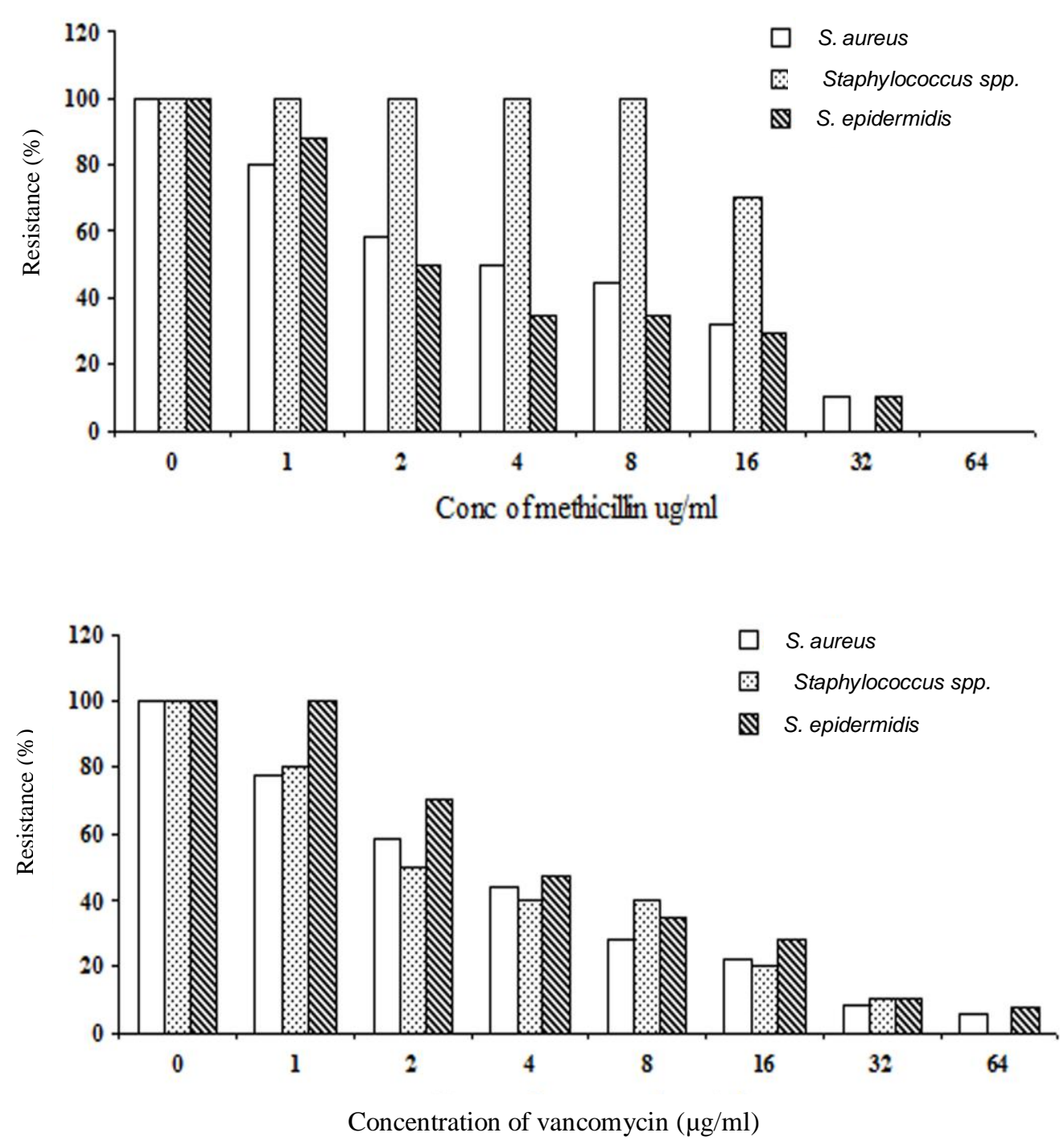

Figure 1. Percentage of methicillin and vancomycin resistance in staphylococci isolates recovered from their MIC data.

showing multidrug resistance and were mec A positive (Figure 2).

\section{DISCUSSION}

As a result of the extensive use of antibiotics, locally isolated staphylococci showed multidrug resistance to the tested antibiotics and also had relatively high MIC to methecillin and vancomycin. Braoios et al. (2009) and Mc clure et al. (2006) reported a correlation between the phenotypic and genotypic results for $S$. aureus as all MRSA had mecA gene while the MSSA lack the gene. In the present study, the MRSA and MRSE isolates were found to have mecA gene thus their phenotypic characterization were similar to their genotypic characterization both confirming their resistance. However, among the MSSA and MSSE, thirty percent of the isolates were found to contain mecA gene. The observation of phenotypically sensitive isolates which contain mecA gene highlights the possible role of horizontal gene transfer (HGT) in the dissemination of antibiotic resistance among MSSA strains. Many studies reported the transfer of mecA by HGT (Wielders et al., 2002; Hanssen et al., 2004). Several reports suggest that SCCmec transfer from methicillin resistant coagulase negative staphylococci (MR-CoNS) to methicillinsusceptible $S$. aureus (MSSA) occurs, although its mechanism remains unknown. MR-CoNS may thus act as a source of SCCmec for MRSA (Barbier et al, 2010). It could be concluded that phenotypic MSS might have partial $\mathrm{SCC} m e c$ that lack the regulatory genes or it could have a mutated SCC mec. Further investigation is needed to determine the presence of unexpressed mecA gene in 


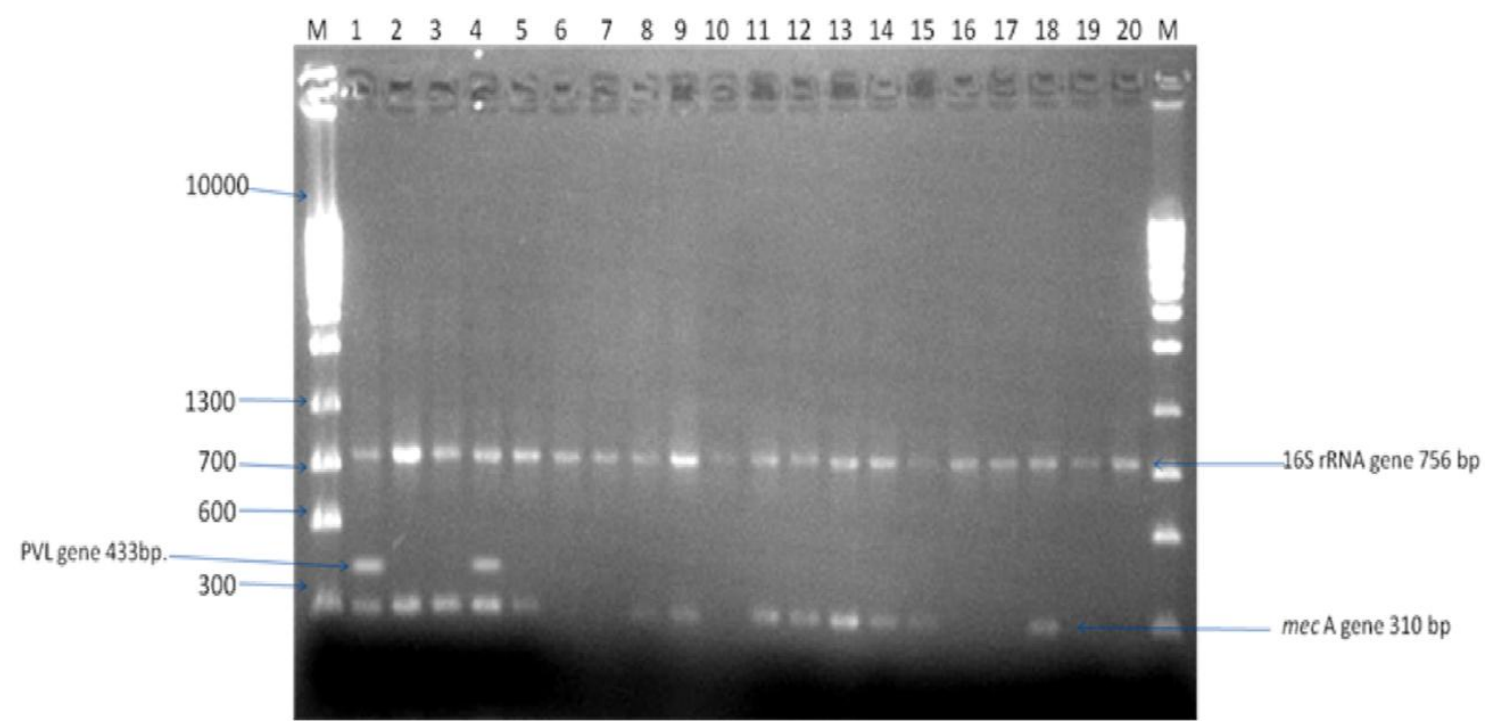

Figure 2. A representative agarose gel electrophoresis of multiplex PCR product resulting from amplification of genomic DNA using the three primer pairs of mecA gene (310 bp), specific region of 16S rRNA gene (756 bp) and the virulence marker PVL (Luk s/f-pv) genes product (433 bp), M is $1 \mathrm{kbp}$; DNA marker. Lanes 1-5 PCR products of resistant $S$. aureus, lanes 6-10: PCR products of sensitive $S$. aureus, Lanes 11-15 PCR products of resistant $S$. epidermidis and lanes: 16-20 PCR products of sensitive $S$. epidermidis.

MSS strains. Consequently, conventional methods for the detection of MRS by disc diffusion method are not sufficient for judging resistance (Fluit et al., 2001).

Multiplex PCR is an accurate method for the detection of the resistant and virulent isolates of staphylococci and it is recommended for a rapid detection and diagnosis (McClure et al., 2006). The choice of PVL genes is based on the finding that staphylococci which contain (luk $S-F$ pvl) genes showed increased disease severity of cutaneous infection (Vandenesch et al., 2003; Deurenberg et al., 2004). Furthermore, it was reported that (luk $S-F p v l$ genes were found in a high proportion $(77 \%)$ in emerging community acquired staphylococcal strains (Naimi et al., 2003; Shukla et al., 2004; Naas et al., 2005).

However the present study showed that only $5 \%$ of the examined isolates harbored the PVL. The $\mathrm{PVL}^{+}$isolate was recovered from pus discharging wound. The antibiotic resistance pattern of these isolates was similar to the other isolates lacking (luk $S-F p v$ ) genes, thus indicating that the presence of (luk $S-F p v$ ) genes does not necessarily indicate higher potency. Similar results were reported in a study where $\mathrm{PVL}^{+}$strains were compared with $\mathrm{PVL}^{-}$mutant strains, both were found equally lethal and virulent (Said-Salim et al., 2005; Diep et al., 2006). The coexistence of PVL and mecA gene was demonstrated in only 5 out of the hundred examined isolates; this is in accordance with the results described by Gillet et al. (2002), Vandenesch et al. (2003) and Zhang et al. (2011) who concluded that PVL locus is carried on bacteriophage that is presently found in small proportion (less than $5 \%$ ) of staphylococcal isolates described worldwide. Accordingly, the previously described principle that PVL is always associated with virulent staphylococci and result in out breaks in soft tissue is still debatable (Zhang et al. 2011). Further studies are required to draw more conclusions regarding the potential association between mecA, PVL and severity of infection. A combination of conventional and multiplex PCR is essential for the detection of the potentially pathogenic Staphylococci including phenotypically resistant and sensitive isolates.

\section{REFERENCES}

Archer GL, Bosilevac JM (2001). Signaling antibiotic resistance in Staphylococci. Science 291:1915-1916.

Barbier F, Ruppe E, Hernandez D, Lebeaux D, Francois P, Felix B, Desprez A, Maiga A, Woerther PL, Gaillard K (2010). Methicillinresistant coagulasenegative staphylococci in the community: high homology of SCCmec IVa between Staphylococcus epidermidis and major clones of methicillin resistant Staphylococcus aureus. J. Infect. Dis. 202:270-281.

Bauer RW, Kirby MDK, Sherris JC, Turck M (1966). Antibiotic susceptibility testing by standard single disc diffusion method. Am. J. Clin. Pathol. 45:493-496.

Berger-Bachi B, Rohrer S (2002). Factors influencing methicillin resistance in staphylococci. Arch. Microbiol. 178:165-171.

Braoios A, Turatti TF, Meredija L, Campos T, Denadai F (2009). Urinary tract infections in non hospitalized patients: etiology and antibiotic resistance patterns. J. Bras. Patol. Med. Lab. 45:449-456.

Chapin KC, Lauderdale TL (2003). Reagents, stains, and media: bacteriology. In: Murray, P. R., E. J. Baron, Jorgensen J. H., Pfaller M. A., and Yolken R. H. (ed.). Manual of clinical microbiology, 8th ed. American Society for Microbiology, Washington, D.C.

Cheesbrough (1984). Text book of diagnostic microbiology, p.1062. W.B. Saunders Company, Philadelphia, Pa.

Deurenberg RH, Vink C, Driessen C (2004). Rapid detection of Panton Valentine Leukocidin from clinical isolates of Staphylococcus aureus 
by real-time PCR. FEMS Microbiol. Lett. 240:225-228.

Diep BA, Carleton HA, Chang RF, Sensabaugh GF, PerdreauRemington $F$ (2006). Roles of 34 virulence genes in the evolution of hospital and community associated streains of methicillin-resistance Staphylococcus aureus. J. Infect. Dis. 193:1495-503

Fluit AD, Visser MR, Schmitz FJ (2001). Molecular detection of antimicrobial resistance. Clin. Microbiol. Rev. 14:836-871.

Gillet $Y$, Issartel B, Vanhems P, Fournet JC, Lina G, Bes M, Vandenesch F, Piemont Y, Brousse N, Floret D, Etienne J (2002). Association between Staphylococcus aureus strains carrying gene for Panton-Valentine leukocidin and highly lethal necrotising pneumonia in young immunocompetent patients. Lancet 359:753-759.

Hanssen AM, Kjeldsen G, Sollid JUE (2004). Local variants of staphylococcal cassette chromosome mec in sporadic methicillin resistant Staphylococcus aureus and methicillin-resistant coagulase negative staphylococci: Evidence of horizontal gene transfer? Antimicrob. Agents Chemother. 48:285-296.

Ito T, Katayama Y, Asada K, Mori N, Tsutsumimoto K, Tiensasitorn C, Hiramatsu K (2001). Structural comparison of three types of staphylococcal cassette chromosome mec integrated in the chromosome in methicillin- resistant Staphylococcus aureus. Antimicrob Agents Chemother. 45:1323-36.

Ito TM, Takeuchi F, Okuma K, Yuzawa H, Hiramatsu K (2004). Novel type $V$ staphylococcal cassette chromosome mec driven by a novel cassette chromosome recombinase, ccrC. Antimicrob. Agents Chemother. 48:2637-51.

Koneman's Color Atlas (1992). Textbook of diagnostic microbiology by Washington C., Winn,Elmer W. and Koneman. p. 987.

Levy SB, Marshall B (2004) Antibacterial resistance worldwide: causes, challenges and responses. Nat. Med. 10:122-129.

Lina G, Piemont Y, Godail-Gamot F, Bes M, Peter MO, Gauduchon V, Vandenesch F, Etienne J (1999). Involvement of Panton-Valentine leukocidin- producing Staphylococcus aureus in primary skin infections and pneumonia. Clin. Infect. Dis. 29:1128-1132.

Mahon CR, Manusekis Jr (1995). Text book of diagnostic microbiology, p.1062. W.B. Saunders Company, Philadelphia, Pa.

McClure J, Conly JM, Lau G (2006). Novel multiplex PCR assay for detection of the staphylococcal virulence marker Panton Valentine Leukocidin genes and simulataneous discrimination of methicillin susceptible from resistance staphylococci. J. Clin. Microbiol. 44:11411144.

Naas T, Fortineau N, Spicq C, Robert J, Jarlier V, Nordmann P (2005). Three-year survey of community-acquired methicillin-resistant Staphylococcus aureus producing Panton-Valentine leukocidin in a French university hospital. J. Hosp. Infect. 61:321-329.

Naimi TS, LeDell KH, Como-Sabetti K, Borchardt SM, Boxrud DJ, Etienne J, Johnson SK, Vandenesch F, Fridkin S, O'Boyle C, Danila RN, Lynfield R (2003). Comparison of community- and health careassociated methicillin resistant Staphylococcus aureus infection. JAMA 290:2976-2984.

NCCLS (1997). Performance Standards for Antimicrobial Disk Susceptibility Tests: Approved Standard M2-A7. National Committee for Clinical Laboratory Standards, Wayne, PA, USA.
Peacock SJ, Silva GD, Justice A (2002). Virulent combinations of adhesin and toxin genes in natural populations of Staphylococcal isolates. Infect. Immun. 70:4987-96.

Prere MF, Baron O, Cohen Bacrie S, Fayet O (2006). Genotype MRSA a new genetic test for rapid identification of Staphylococci and detection of mecA gene. Pathol. Biol. 54:502-505.

Said-Salim B, Mathema B, Braughton K, Davis S, Sinsimer D, Eisner W, Likhoshvay Y, Deleo FR, Kreiswirth BN (2005). Differential distribution and expression of Panton-Valentine leukocidin among community-acquired methicillin-resistant Staphylococcus aureus strains. J. Clin. Microbiol. 43:3373-3379.

Sambrook J, Russel J, Russell DW (2001). Commonly used techniques in molecular cloning, In Sambrook, $J$ and Russell $D^{\mathrm{w}}\left(3^{\text {rd }}\right.$ ed). Molecular cloning: A laboratory manual. Cold Spring Harbor Laboratory Press, New York, USA, A8.9-A8.10.

Shukla SK, Stemper ME, Ramaswamy SV, Conradt JM, Reich R, Graviss EA, Reed KD (2004). Molecular characteristics of nosocomial and Native American community-associated methicillin-resistant Staphylococcus aureus clones from rural Wisconsin. J. Clin. Microbiol. 42:3752-3757.

Todar K (2005). Staphylococcus Todar's online Textbook of Bacteriology (http:// Textbook of bacteriology.net/staph.html).

Van Hal SJ, Stark D, Lock Wood B (2007). MRSA detection: comparison of two molecular methods (IDI - MRSA® PCR assay and Genotype $\AA$ MRSA Direct PCR assay with three selective MRSA agars (MRSA ID $\AA$ MRSA select $\AA$ and CHROM agar MRSA) For infection control swabs. J. Clin. Microbiol.

Van Pelt-Verkuil E, Van Belkum A, Hays JP (2008). Principles and technical aspects of PCR amplification. Springer, Rotterdam and the Netherlands.

Vandenesch F, Naimi T, Enright MC, Lina G, Nimmo GR, Heffernan H, Liassine N, Bes M, Greenland T, Reverdy ME, Etienne J (2003). Community-acquired methicillin-resistant Staphylococcus aureus carrying Panton-Valentine leukocidin genes: worldwide emergence. Emerg. Infect. Dis. 9:978-984.

Washington JA, Wood GL (1995). Antimicrobial susceptibility tests: Dilution and disc diffusion methods. In: Manual of Clinical Microbiology. pp. 1327-1331.

Wielders CL, Fluit AC, Brisse S, Verhoef J, Schmitz FJ (2002). mecA gene is widely disseminated in Staphylococcus aureus population. $\mathrm{J}$. Clin. Microbiol. 40:3970-5.

Zhang K, Sparling J, Chow BL, Elsayed S, Hussain Z, Church DL, Gregson DB, Louie T, Conly JM (2004). New quadriplex PCR assay for detection of methicillin and mupirocin resistance and simultaneous discrimination of Staphylococcus aureus from coagulase-negative staphylococci. J. Clin. Microbiol. 42:4947-4955.

Zhang M, Ito T, Li S, Jin J, Takeuchi F, et al (2011). Identification of the third type of PVL phage in ST59 methicillin-resistant Staphylococcus aureus (MRSA) strains. FEMS Microbiol. Lett. 323:20-28. 